\title{
Sporogenesis and toxin A production by Clostridium difficile
}

\author{
J. M. KETLEY, T. J. MITCHELL, S. C. HASLAM, J. STEPHEN, D. C. A. CANDY* AND \\ D. W. BURDON†
}

Department of Microbiology, University of Birmingham, P.O. Box 363, Birmingham B15 2TT, *Insitute of Child Health, Francis Road, Birmingham B16 8ET and †The General Hospital, Steelhouse Lane, Birmingham B4 6NH

Summary. The kinetics of spore production by Clostridium difficile were not paralleled
by release of $C$. difficile toxin A in vitro. Toxin A was not found to be associated with
either purified whole spores or spore coats. Residual traces of toxin A detected in spore
contents were almost certainly derived from contaminating vegetative cell debris.
Thus, toxin A is unlikely to be a spore constituent or associated with sporogenesis.

\section{Introduction}

The role of Clostridium difficile in colitis associated with antimicrobial therapy is now well established (Bartlett et al., 1978; George et al., 1978). The organism produces at least four toxins of potential pathogenic relevance: toxin A (enterotoxin), toxin B (cytotoxin) (Taylor et al., 1980 and 1981; Burdon et al., 1981; Lyerly et al., 1982), a myoelectric factor (Justus et al., 1982) and a recently reported labile toxin (Banno et al., 1984). Ketley et al. (1984) reported that both toxins A and $B$ appear to be produced and released during the decline phase of growth in vitro. It was recognised that such a pattern could reflect an association of toxigenesis with sporulation as is the case with $C$. perfringens type $\mathrm{A}$ enterotoxin (Frieben and Duncan, 1973) and C. botulinum $\mathrm{C}_{2}$ toxin (Yamakawa $e t$ al., 1983).

Preliminary work in our laboratory (unpublished results, alluded to by Ketley et al., 1984), based on studies with a poorly sporulating strain (no. 23289), suggested no correlation between the level of sporulation obtained in several different media and the amount of extracellular toxin A produced. In this paper we present positive evidence to indicate that $C$. difficile toxin $\mathrm{A}$ is not associated with the production of spores or their constituents.

\section{Materials and methods}

\section{Bacterial strains}

C. difficile strain 8089 (a clinical isolate able to produce

Received 12 Sep. 1985; accepted 30 Sep. 1985.

Address for correspondence: Dr J. Stephen, Department of Microbiology, University of Birmingham, Birmingham B15 2TT. both toxins $\mathrm{A}$ and $\mathrm{B}$ ) was chosen for this work because of its high level of sporulation. Previous experience showed that laboratory maintenance of at least some strains over long periods leads to a loss of spore production. For the duration of the work described in this paper, this strain was a prolific sporeformer.

\section{Sporulation Medium}

Several sporulation media were examined (Duncan and Strong, 1968; Gould, 1971; Wilson et al., 1982; Yamakawa et al., 1983). The highest levels of sporulation were achieved when strain 8089 was grown in the medium described by Wilson et al. (1982): Trypticase Peptone (BBL Microbiology Systems, Cockeysville, MD, USA) $90 \mathrm{~g} / \mathrm{L}$, Proteose Peptone No. 3 (Difco) $5.0 \mathrm{~g} / \mathrm{L}$, $\left(\mathrm{NH}_{4}\right)_{2} \mathrm{SO}_{4} 1.0 \mathrm{~g} / \mathrm{L}$, TRIS $1.5 \mathrm{~g} / \mathrm{L}, p \mathrm{H} 7 \cdot 4$. The medium was autoclaved and then prereduced for $\geqslant 24 \mathrm{~h}$.

\section{Growth conditions}

Strain 8089 was inoculated from human-blood agar into $10 \mathrm{ml}$ of sporulation medium and incubated at $37^{\circ} \mathrm{C}$ for $48 \mathrm{~h}$ in anaerobic conditions. Cultures were heat shocked at $75^{\circ} \mathrm{C}$ for $20 \mathrm{~min}$ and rapidly cooled on ice before a $10 \%$ re-inoculation into $10 \mathrm{ml}$ of fresh sporulation medium. For experiments on the kinetics of sporulation and toxin-A release, a further two such heat-shock treatments on strain 8089 were performed. This starter culture, enriched for sporulating organisms, was finally inoculated into $100 \mathrm{ml}$ of fresh sporulation medium, giving an initial total count of $c .3 \times 10^{7} \mathrm{cells} / \mathrm{ml}$, and incubated anaerobically at $37^{\circ} \mathrm{C}$. Samples $(1 \mathrm{ml})$ were taken by the method described by Ketley et al. (1984), so as to minimise any disturbance in anaerobic conditions during the early stages of growth.

Cultures for production of purified spore preparations were inoculated after three heat-shock treatments (as above) into $500 \mathrm{ml}$ of fresh sporulation medium and incubated anaerobically at $37^{\circ} \mathrm{C}$. Different cultures were 


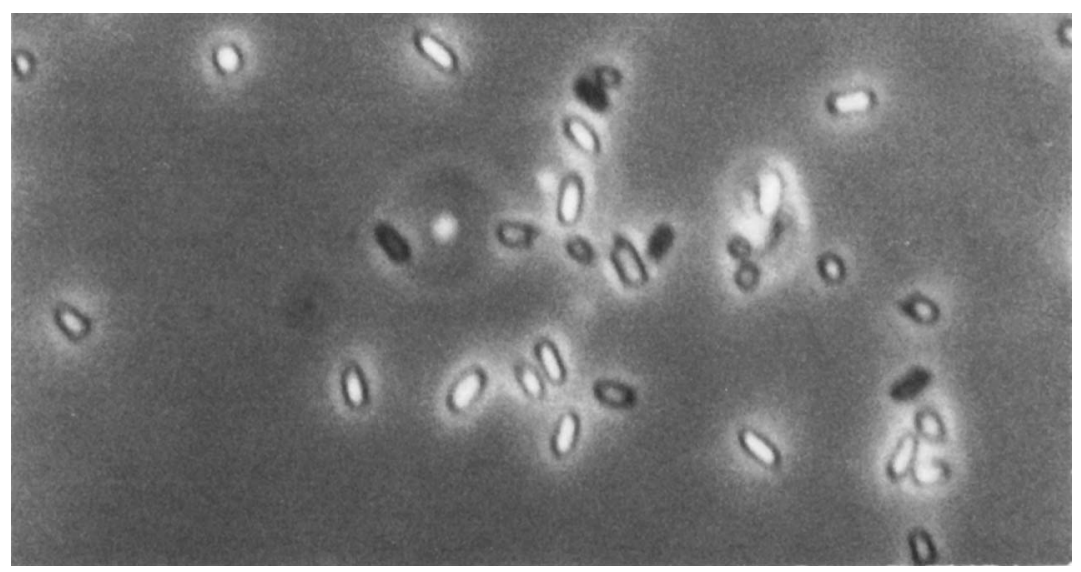

Fig. 1. Cleaned spore preparation as shown by phase-contrast microscopy. $\times 630$.

used for bulk spore production because larger volumes were used which made continuous sampling, though desirable, logistically more difficult. All anaerobic incubations were in anaerobe jars containing the Gas Pak system (BBL Microbiology Systems).

\section{Preparation of spore suspensions}

Spore suspensions were prepared and cleaned (Frieben and Duncan, 1973) as follows. Organisms were harvested by centrifugation at $15000 \mathrm{~g}$ at $4 \mathrm{C}$ for $35 \mathrm{~min}$ and the supernate stored at $-20 \mathrm{C}$. Resultant pellets were resuspended in $10 \mathrm{ml}$ distilled water. Suspensions were then ultrasonicated at 50 watts, for a total time of $12 \mathrm{~min}$ during which they were constantly cooled on ice. The particle fraction released by ultrasonication was then washed 12 times at $4 \mathrm{C}$ with $5 \mathrm{ml}$ distilled water and finally resuspended in $6 \mathrm{ml}$ of distilled water. Liberation of spores from sporangial remnants and the removal, by washing, of cell debris was monitored by phase-contrast microscopy (fig. 1). Cleaned spore preparations were stored at $4 \mathrm{C}$.

\section{Preparation of spore coats and contents}

The cleaned spore preparation $(3 \mathrm{ml})$ was centrifuged at $11000 \mathrm{~g}$ at $4 . \mathrm{C}$ for $2 \mathrm{~min}$ and the pellet resuspended in 1 $\mathrm{ml}$ of distilled water. This preparation was treated to produce spore coats and spore contents by Mickle disintegration at $4 \mathrm{C}$ for $40 \mathrm{~min}$ in the presence of $1 \mathrm{~g}$ of glass beads (Sigma) (Frieben and Duncan, 1973). The treated preparation was then examined by phase-contrast microscopy for the loss of whole, phase-bright spores. After centrifugation, the spore contents were removed and spore coats resuspended in $1 \mathrm{ml}$ of egg-white lysozyme (Sigma) $75 \mu \mathrm{g} / \mathrm{ml}$ and incubated at $37^{\circ} \mathrm{C}$ for $2 \mathrm{~h}$. After enzyme treatment the coats were centrifuged and washed three times in $1.5 \mathrm{ml}$ of distilled water and finally resuspended in $3 \mathrm{ml}$ of distilled water.

\section{Extraction of toxins from whole spores and spore coats}

Three $\mathrm{ml}$ of intact spore preparation and $3 \mathrm{ml}$ of washed spore coats were treated with (a) distilled water, or (b) $0.2 \mathrm{M}$ mercaptoethanol $(p \mathrm{H} \mathrm{10.0)}$, or (c) $1 \mathrm{M} \mathrm{NaCl}$. Alkaline mercaptoethanol extracts $C$. perfringens type $\mathrm{A}$ enterotoxin (Frieben and Duncan, 1973) and C. botulinum $\mathrm{C}_{2}$ toxin (Yamakawa et al., 1983) from spore coats. $\mathrm{NaCl}$ extracts toxin A from $C$. difficile culture pellets (Florin and Thelestam, 1981; T. J. Mitchell, unpublished results). After incubation for $2 \mathrm{~h}$ at $37^{\circ} \mathrm{C}$, the preparations were centrifuged at $11000 \mathrm{~g}$ at $4^{\circ} \mathrm{C}$ for $5 \mathrm{~min}$ and supernates extensively dialysed against $0.05 \mathrm{M} \mathrm{TRIS} / \mathrm{HCl}$ $\left(p \mathrm{H} \mathrm{7.5)}\right.$ and stored at $4^{\circ} \mathrm{C}$ before toxin assay.

\section{Cell and spore counts}

Total cell and spore counts were estimated with a Thoma chamber and phase contrast microscopy. Vegetative cells and whole spores were identified as being phase dark and phase bright respectively.

Viable spore counts were estimated by the method of Borriello and Honour (1981): after an alcohol shock procedure, $0.01-\mathrm{ml}$ volumes of serial dilutions were plated on to human-blood agar and incubated anaerobically at $37^{\circ} \mathrm{C}$. Viable spore counts taken throughout the procedure for the production of clean spores were low and variable in comparison with the corresponding total spore number (see Discussion).

\section{Toxin-A assay}

Toxin A was assayed by enzyme-linked immunosorbent assay as described by Redmond et al. (1985). The limit of detection of this assay is typically $5 \mathrm{ng} / \mathrm{ml}$. The total yield of toxin $\mathrm{A}$ in the system was calculated by summation of toxin A obtained at each stage of fractionation or extraction. Yields of toxin A were expressed either as stage yields or as percentages of the total present in the system. 
a) EXPERIMENT 1

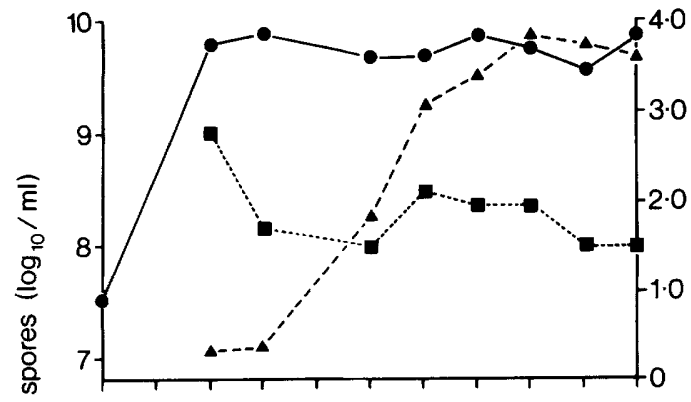

b) EXPERIMENT 2

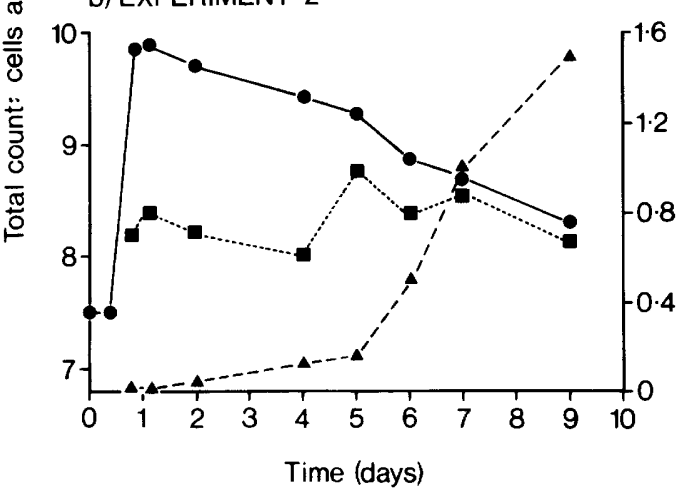

Fig. 2. (a) Experiment 1, (b) experiment 2. Total vegetative cell $(-\bullet)$ and spore counts (-). Extracellular toxin A (- -) concentration during in-vitro culture of $C$. difficile strain 8089 .

\section{Results}

\section{Kinetics of sporulation and toxin- $A$ release}

Cell and spore counts and extracellular toxin-A levels during the growth of strain 8089 in sporulation medium are given in fig. 2. In experiment 1 (fig. 2a) the first sample was taken 2 days after inoculation; subsequent samples did not show the previously described characteristic drop in total cell numbers (Ketley et al., 1984). The number of spores at day 2 was high, declined by day 3 , then fluctuated for the remaining 7 days. Extracellular toxin-A levels were low on days 2 and 3 , but began to rise dramatically between days 3 and 5 , i.e., at least $48 \mathrm{~h}$ after the appearance of spores in culture. No sample was taken on day 4.

In experiment 2 (fig. 2b) samples were taken at earlier time points. After a 10 -h lag phase, strain 8089 grew logarithmically for $10 \mathrm{~h}$, and then entered a stationary phase of $5 \mathrm{~h}$ with a subsequent decline phase over the next 9 days. Spores were present in the culture immediately following logarithmic growth and the number of spores did not alter appreciably over the following 8 days. Extracellular
toxin-A levels did not begin to rise until $48 \mathrm{~h}$ after inoculation; the most significant rise was seen after 5 days. The patterns of spore- and extracellular toxin-A production were almost identical to those seen in experiment 1 (fig. 2a) apart from an apparent 24-h shift in the pattern of toxin-A release. This shift accentuated the lack of correlation between spore formation and toxin-A release seen in experiment 1 (fig. 2a).

When these experiments were repeated twice in the tryptic nitrate broth of Ketley et al. (1984) similar results were obtained. This shows that the separation of toxin-A release from spore production is not unique to the sporulation medium described here.

\section{Toxin A association with spore fractions}

Cell and spore counts of (i) culture samples taken at days 5 (experiment 3 ) and 10 (experiment 4), (ii) purified spore preparations, and (iii) suspensions of spore contents and coats (generated as outlined in fig. 3) are given in table I. Total cell and spore counts are calculated for the total volume of the suspension at each stage of the procedure. In experiment 3 the culture was harvested 5 days after inoculation; this was predicted to be the earliest time at which sufficiently high levels of toxin A would be present for analysis (fig. 2a). However it was later shown (experiment 2; fig 2b) that the exact time of this rise is variable. This probably accounted for the low toxin-A levels found in experiment 3 (table II). In experiment 4 the culture was harvested at 10 days to provide spore preparations derived at a time when levels of toxin A were high.

Spore losses occurred after ultrasonication and subsequent washing steps. Mickle disintegration successfully disrupted $99 \%$ of spores in purified spore preparations (table I). The viability of spores (particularly in culture samples and ultrasonicated pellets) was low and variable (data not shown) in comparison with their corresponding total spore counts (see Discussion).

In experiment 3 , a culture harvested at 5 days had $2.3 \times 10^{12}$ total vegetative cells and $4.3 \times 10^{10}$ phasebright spores and had released $29.66 \mu \mathrm{g}$ of toxin A into the culture supernate (i.e., $97 \cdot 8 \%$ of the total toxin A present in the system at the time of harvest; tables I and II). Ultrasonication of the cell pellet liberated only a further $1 \%$ of total toxin A. The initial four steps of the ultrasonicated crude spore preparation removed $1 \%$ of total toxin $\mathrm{A}$ and subsequent washes did not contain any further detectable toxin A. Half the purified spore preparation was Mickle disintegrated to provide spore 


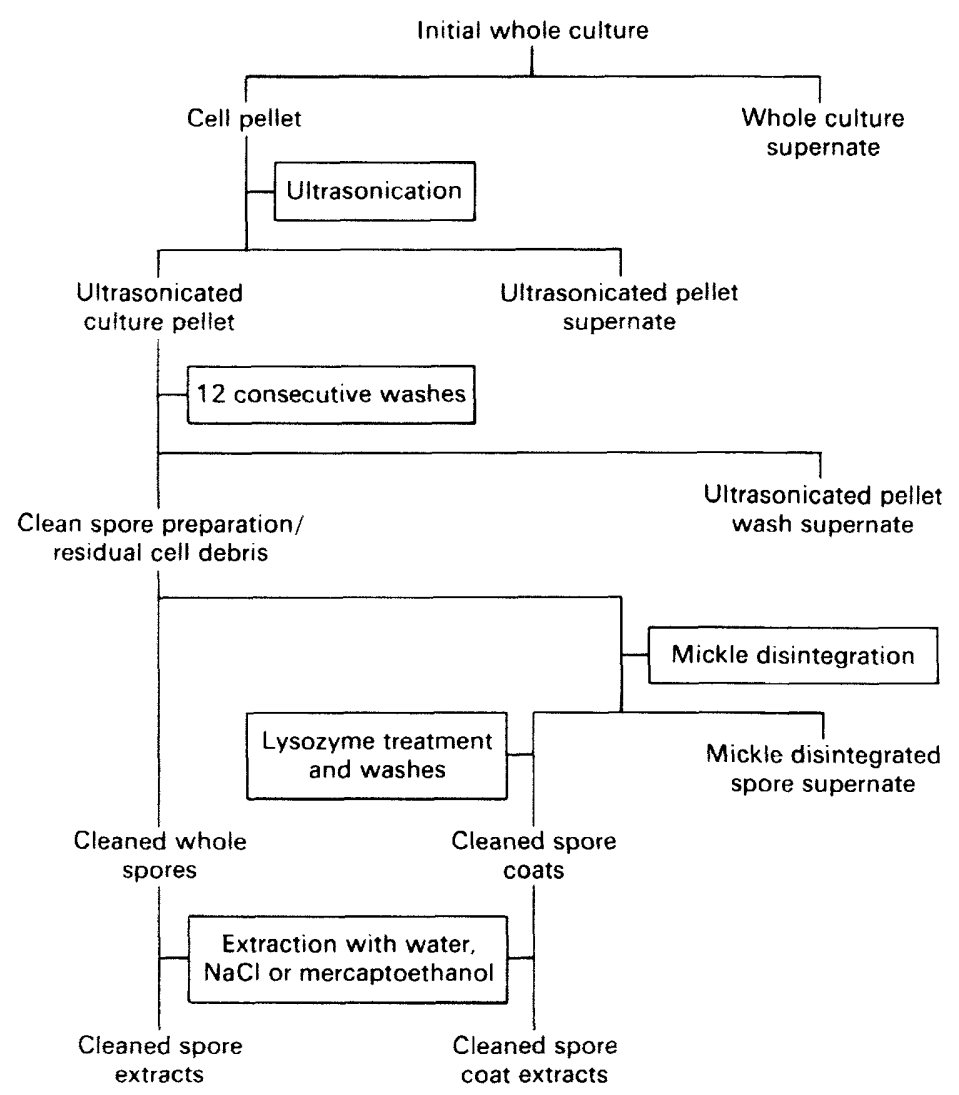

Fig. 3. Protocol for the production of a cleaned spore preparation, Mickle disintegrated spore supernate, cleaned spore extracts and spore coat extracts.

Table I. Total cell and spore numbers at various stages in the preparation of purified whole spores and spore coats

\begin{tabular}{|c|c|c|c|c|c|}
\hline C. difficile preparation & $\begin{array}{l}\text { Volume } \\
\text { (ml) }\end{array}$ & $\begin{array}{l}\text { Experiment } \\
\text { number }\end{array}$ & $\begin{array}{l}\text { Total vegetative } \\
\text { cell count** }\end{array}$ & $\begin{array}{l}\text { Total spore } \\
\text { count }\end{array}$ & $\begin{array}{l}\text { Total spore-stage yield } \\
\text { (percentage of initial total) }\end{array}$ \\
\hline Initial whole culture* & 500 & $\left\{\begin{array}{l}3 \\
4\end{array}\right.$ & $\begin{array}{l}2.3 \times 10^{12} \\
1.6 \times 10^{12}\end{array}$ & $\begin{array}{l}4.3 \times 10^{10} \\
7.3 \times 10^{11}\end{array}$ & $\begin{array}{l}100 \\
100\end{array}$ \\
\hline $\begin{array}{l}\text { Ultrasonicated culture } \\
\text { pellet }{ }^{\dagger}\end{array}$ & 10 & $\left\{\begin{array}{l}3 \\
4\end{array}\right.$ & $\begin{array}{l}1.75 \times 10^{10} \\
2.5 \times 10^{9}\end{array}$ & $\begin{array}{l}2 \cdot 1 \times 10^{10} \\
2 \cdot 1 \times 10^{11}\end{array}$ & $\begin{array}{l}48 \cdot 8 \\
28 \cdot 8\end{array}$ \\
\hline Whole spore preparation+ & 3 & $\left\{\begin{array}{l}3 \\
4\end{array}\right.$ & $\begin{array}{c}2.0 \times 10^{9} \\
\text { NT }\end{array}$ & $\begin{array}{l}7 \cdot 9 \times 10^{9} \\
2 \cdot 5 \times 10^{10}\end{array}$ & $\begin{array}{r}18 \cdot 4 \\
3 \cdot 4\end{array}$ \\
\hline Spore coat preparation $\S$ & 3 & $\left\{\begin{array}{l}3 \\
4\end{array}\right.$ & $\begin{array}{l}\text { NT } \\
\text { NT }\end{array}$ & $\begin{array}{l}6.0 \times 10^{7} \\
2.4 \times 10^{8}\end{array}$ & $\begin{array}{l}0.14 \\
0.03\end{array}$ \\
\hline
\end{tabular}

* Culture harvested at 5 days (experiment 3) and 10 days (experiment 4).

+ Pellet derived from the whole culture by centrifugation of cells and spores. After resuspension the pellet was ultrasonicated to give free spores and sporangial debris (fig. 3).

$\ddagger$ Whole spore preparation derived by centrifugation, washing of the ultrasonicated pellet and final resuspension in $6 \mathrm{ml}$ of distilled water (fig. 3).

$\S$ Spore coats derived by Mickle disintegration of $3 \mathrm{ml}$ of whole spore preparation (fig. 3 ).

- Number of phase-bright spores remaining after Mickle disintegration.

** The number is calculated for the total volume shown in column 1 . 
Table II. Distribution of toxin A in culture supernate, ultrasonicated extract of culture pellet, Mickle-disintegrated spore supernate and extracts of whole spores and spore coats

\begin{tabular}{|c|c|c|c|c|}
\hline C. difficile preparation & $\begin{array}{l}\text { Volume } \\
\text { (ml) }\end{array}$ & $\begin{array}{l}\text { Experiment } \\
\text { number* }\end{array}$ & $\begin{array}{l}\text { Stage yield of } \\
\text { toxin } \mathrm{A}(\mu \mathrm{g})\end{array}$ & $\begin{array}{c}\text { Percentage of total } \\
\text { toxin A } \dagger\end{array}$ \\
\hline Whole culture supernate $\ddagger$ & 500 & $\left\{\begin{array}{l}3 \\
4\end{array}\right.$ & $\begin{array}{r}29 \cdot 0 \\
152 \cdot 5\end{array}$ & $\begin{array}{l}97 \cdot 8 \\
39 \cdot 2\end{array}$ \\
\hline $\begin{array}{l}\text { Ultrasonicated pellet } \\
\text { supernatant }\end{array}$ & 10 & $\left\{\begin{array}{l}3 \\
4\end{array}\right.$ & $\begin{array}{c}0 \cdot 34 \\
220 \cdot 0\end{array}$ & $\begin{array}{r}1 \cdot 1 \\
56 \cdot 6\end{array}$ \\
\hline $\begin{array}{l}\text { Ultrasonicated pellet } \\
\text { washes }\end{array}$ & $5 \S$ & $\left\{\begin{array}{l}3 \\
4\end{array}\right.$ & $\begin{array}{r}0.30 \\
15 \cdot 84\end{array}$ & $\begin{array}{l}1 \cdot 01 \\
4 \cdot 0\end{array}$ \\
\hline Cleaned spore extracts & $1 \cdot 0$ & 3 and 4 & BLD & 0 \\
\hline $\begin{array}{l}\text { Mickle disintegrated spore } \\
\text { supernatant }\end{array}$ & $2 \cdot 5$ & $\left\{\begin{array}{l}3 \\
4\end{array}\right.$ & $\begin{array}{l}0 \cdot 016 \\
0 \cdot 21\end{array}$ & $\begin{array}{l}0.054 \\
0 \cdot 054\end{array}$ \\
\hline $\begin{array}{l}\text { Lysozyme treatment } \\
\text { and washes }\end{array}$ & $5 \cdot 5$ & 3 and 4 & BLD & 0 \\
\hline Spore coat extracts $\uparrow$ & $1 \cdot 0$ & 3 and 4 & BLD & 0 \\
\hline \multicolumn{5}{|c|}{ 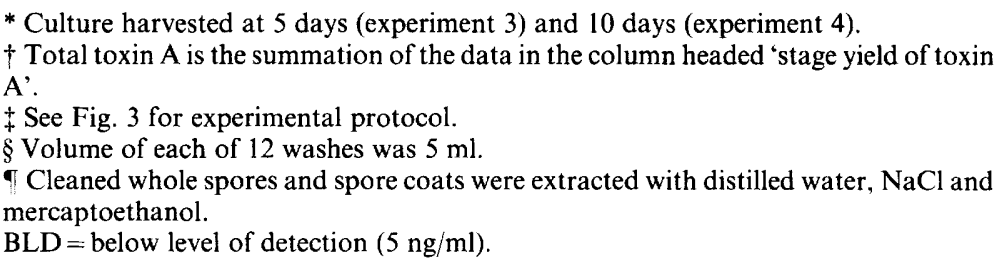 } \\
\hline
\end{tabular}

contents and coats. Spore contents contained $0.054 \%$ of the total toxin A originally present in this culture. No detectable toxin A could be extracted from either whole spores or spore coats.

In experiment 4 a culture harvested at 10 days had $1.6 \times 10^{12}$ vegetative cells and $7.3 \times 10^{11}$ phasebright spores and had released $152.5 \mu \mathrm{g}$ of toxin A into the culture medium (i.e., $39 \cdot 2 \%$ of total toxin A present in the system at the time of harvest; tables I and II). Although the amount of cell-associated toxin A released by ultrasonication was much greater $(56.6 \%)$ than in experiment 3 , there was no extractable toxin $\mathrm{A}$ in whole spores or spore coats (table II). Again, only a small amount of toxin A $(0.054 \%$ of the total) was detected in the sporecontents fraction.

\section{Discussion}

The patterns of spore production and release of toxin $\mathrm{A}$ in culture indicate that toxin-A production does not correlate with spore production. Spores appear early in culture and their levels fluctuate in a manner apparently unrelated to the rise of toxin $\mathrm{A}$ observed in extended stationary or decline phase.

Toxin A was not significantly associated with any spore constituent. Here we have shown that only trace amounts of toxin A present in a sporulating culture of $C$. difficile were associated with the sporecontents fraction; this small amount of toxin A, released by Mickle disintegration, may well arise from contaminating vegetative cell debris, the last traces of which were always difficult to remove. The ratio of the amounts of toxin $A$ associated with spore contents in experiments 3 and 4 was identical to the ratio of the total amounts of toxin present in the system and bore no relationship to the numbers of spores present in the original culture or, more importantly, immediately before Mickle disintegration.

No detectable toxin A could be extracted with mercaptoethanol from purified whole spores or spore coats. This contrasts with the results obtained with C. botulinum (Yamakawa et al., 1983) or C. perfringens type A (Frieben and Duncan, 1973). $\mathrm{NaCl}(1 \mathrm{M})$ also failed to extract toxin from spores despite the fact that it extracts toxin A from $C$. difficile vegetative cells (Florin and Thelestam, 1981; T. J. Mitchell, unpublished results).

The validity of our conclusions relative to the absolute distribution of toxin $\mathrm{A}$ in, on, or outside vegetative cells and spores clearly rests on assumptions regarding the stability of toxin $A$ to the various treatments used. Treatment with $1 \mathrm{M} \mathrm{NaCl}$ 
does not inactivate toxin A (see Methods), and $0.2 \mathrm{M}$ mercaptoethanol treatment does not reduce ELISA titres of toxin A if the mercaptoethanol is thereafter effectively removed (J. M. Ketley, unpublished results). It is clear from results given in table II that washing ultrasonicated pellets with water did not inactivate toxin $\mathrm{A}$, since water washes in experiment 4 contained significant amounts of toxin $\mathrm{A}$. The effect of ultrasonication on purified toxin $A$ has not been determined, but detectable toxin $\mathrm{A}$ is known to be released from cells by such treatment (Ketley $e t$ al. 1984).

There are two probable reasons for the observed discrepancies between viable counts obtained from spores and the corresponding total spore counts. First, the results may reflect sub-optimal germination conditions found with non-supplemented blood-agar media (Wilson et al.. 1982). Second, a general downward trend in total spore counts (due to spore loss throughout the purification procedure before Mickle disintegration) was not reflected in the viable spore counts, i.e., the ratio of total spores to viable spores did not remain constant. Viable spore counts either remained level or rose, perhaps reflecting an improvement in germination capa-

\section{REFERENCES}

Banno Y. Kobayashi T. Kono H. Watanabe K. Ueno K. Nozawa Y 1984 Biochemical characterization and biologic actions of two toxins (D-1 and D-2) from Clostridium difficile. Reviews of Infectious Diseases 6 (suppl. 1): 511-520.

Bartlett J G, Chang T W. Gurwith M, Gorbach S L. Onderdonk A B 1978 Antibiotic-associated pseudomembranous colitis due to toxin-producing clostridia. New England Journal of Medicine 298:531-534.

Borriello S P, Honour P 1981 Simplified procedure for the routine isolation of Clostridium difficile from faeces. Journal of Clinical Pathologi 34:1124-1127.

Burdon D W. Thompson H. Candy D C A. Kearns M, Lees D. Stephen J 1981 Enterotoxin(s) of Clostridium difficile. Lancet 2:258 259.

Duncan C L. Strong D H 1968 Improved medium for sporulation of Clostridium perfringens. Applied Microbiology 16:82 89.

Florin I. Thelestam M 1981 Intoxication of cultured human lung fibroblasts with Clostridium difficile toxin. Infection and Immunity 33:67-74.

Fricben W R. Duncan C L 1973 Homology between enterotoxin protein and spore structural protein in Clostridium perfringens Type A. European Journal of Biochemistry 39:393 401

George R H. Symonds J M. Dimock F. Brown J D. Arabi Y, Shinagawa N. Keighley M R B. Alexander-Williams J. Burdon D W 1978 Identification of Clostridium difficile as a cause of pseudomembranous colitis. British Medical Journal $1: 695$

Gould G W 1971 Methods for studying bacterial spores. In: Norris $J$ R. Ribbons D W (eds) Methods in microbiology 6A. chapter VI. Academic Press, London. pp 327-381. bility following ultrasonication and extensive washing of spores. However, in both experiments, Mickle disintegration caused significant drops in viable spore counts and in total spore counts.

Toxin-A production seems to correlate with the total number of vegetative cells in relation to the time of culture. Toxin-A levels were higher when more cells were present during decline or extended stationary phase, and cell-associated toxin-A levels were higher in older cultures. These observations suggest that toxin $A$ is being produced by vegetative cells remaining throughout decline or an extended stationary phase.

We conclude that in contrast to $C$. botulinum $\mathrm{C}_{2}$ toxin (Yamakawa et al., 1983) and C. perfringens type A enterotoxin (Frieben and Duncan, 1973), $C$. difficile toxin $\mathrm{A}$ is not associated to any significant degree with extractable constituents of spores, and, furthermore, does not appear to be associated with sporogenesis.

JS, DCAC and SWB thank the Medical Research Council for generous support to JK and $\mathrm{SCH}$, and the Science and Engineering Research Council in association with Pfizer Central Research for a CASE studentship to TM.

Justus P G. Martin J L, Goldberg D A. Taylor N S, Bartlett J G, Alexander R W, Mathias J R 1982 Myoelectric effects of Clostridium difficile: Motility-altering factors distinct from its cytotoxin and enterotoxin in rabbits. Gastroenterology 83:836-843.

Ketley J M. Haslam S C, Mitchell T J, Stephen J, Candy D C A, Burdon D W 1984 Production and release of toxins A and B by Clostridium difficile. Joumal of Medical Microbiology. 18:385-391.

Lyerly D M. Lockwood D E, Richardson S H. Wilkins T D 1982 Biological activities of toxins A and B of Clostridium difficile. Infection and Immunity 35:1147-1150.

Redmond S C, Ketley J M, Mitchell T J, Stephen J, Burdon D W, Candy D C A 1985 Detection of Clostridium difficile enterotoxin (toxin A) by ELISA and other techniques. In: Collins CH, Grange JM (eds) Isolation and identification of micro-organisms of medical and verterinary importance. Society of Applied Bacteriology, Technical Series 21, Academic Press. London 237250.

Taylor N S. Thorne G M, Bartlett J G 1980 Separation of an enterotoxin from the cytotoxin of Clostridium difficile. Clinical Research 28:285A

Taylor N S. Thorne G M, Bartlett J G 1981 Comparison of two toxins produced by Clostridium difficile. Infection and Immunity 34:1036 1043

Wilson K H. Kennedy M J, Fekety F R 1982 Use of sodium taurocholate to enhance spore recovery on a medium selective for Clostridium difficile. Journal of Clinical Microbiology 15:443-446.

Yamakawa K, Nishida S. Nakamura S $1983 \mathrm{C}_{2}$ toxicity in extract of Clostridium botulinum Type $\mathrm{C}$ spores. Infection and Immunity 41:858-860. 